Specialty care in the community

\section{Delivering specialist services in the community: implications for the profession} John F Mayberry

\section{Education, training and new ways of working}

$\mathrm{T}$ he Postgraduate Medical Journal continues to review the implications and consequences of providing specialist healthcare services in the community. In the January issue, the political imperatives for changing the nature of healthcare delivery in the UK were set out. ${ }^{1-6}$

In this issue, we focus on what it might mean for the profession. Dr Mary Armitage, of the Royal College of Physicians, describes how all healthcare workers delivering specialist services in the community must work to agreed national standards of practice. The need for training programmes to achieve these specialist competencies is emphasised. Professor Mayur Lakhani, of the Royal College of General Practitioners, explores the interface between generalists and specialists and considers the relationship between consultants and general practitioners is one of the most pressing questions in the National Health Service today. He believes the reconfiguration of health services demands a sound education and training strategy and that new training models will emerge where trainees move seamlessly between what are currently defined as primary and secondary care.

Postgrad Med J 2007;83:71.

doi: $10.1136 /$ pgmi.2006.056952

Correspondence to: John F Mayberry,

Postgraduate Medical Journal, Leicester General Hospital, Gwendolen Road, Leicester LE5 4PW, UK; pmi@bmjgroup.com

\section{REFERENCES}

1 Blair T. Improving services for patients in the community: the Rt Hon Tony Blair MP, UK Prime Minister. Postgrad Med J 2007;83:1.

2 Mayberry JF. Providing specialist services in the community. Postgrad Med J 2007;83:2.

3 Cameron D. Delivery of healthcare outside acute hospitals: the Rt Hon David Cameron MP, Leader of the Conservative Party and Leader of the Opposition. Postgrad Med J 2007;83:2.

4 Campbell M. Quality care in the community: the Rt Hon Sir Menzies Campbell MP, Leader of the Liberal Democrats. Postgrad Med J 2007;83:3.

5 Donaldson L. The educational needs of doctors delivering specialist services in the community. Postgrad Med J 2007;83:3.

6 Azam N, Moshkovska T, Mayberry JF. Views of specialist registrars on specialty care in the community: employment prospects and the need for additional training. Postgrad Med J 2007;83:59-61

\title{
COMMENTARIES
}

\section{Reconfiguring health services to provide care closer to home}

\section{Mayur Lakhani}

Specialists and generalists working together in the community for the benefit of patients

A s a practicing general practitioner, I am well aware of the fragmentation and disruption that patients have as they traverse the health and social care journey. I also realise that patients need a combination of generalism and specialism in the community. Currently, services are organised around the convenience of organisations and professionals rather than the clinical needs of patients. For example, community nurses may provide services according to who their employer is rather than the clinical need of the patient, although they are all members of the National Health Service (NHS) family.

Health service policy in England promotes "care closer to home", reconfiguration of services and an ambitious 18week target from referral by a general practitioner to completion of treatment by 2009. The new policies pose a formidable implementation challenge for local health communities and will require new ways of working and better models of care. Most importantly it will need to be underpinned by a sound education and training strategy. Support will also be required to develop other skills-in leadership, teamwork and information communication technology.

In all these endeavours leadership from professional organisations and doctors will be essential. In 2006, the Royal College of General Practitioners (RCGP) and the Royal College of Physicians (RCP) issued a joint statement called "Making the best use of doctors' skills-a balanced partnership". ${ }^{2}$ The Colleges stated that: "new models of healthcare must be developed to meet the aspirations and needs of patients in the new and modern NHS and that doctors working together across traditional organisational boundaries are central to such new models. The Colleges believe that specialists and generalists working in strong colla- borative arrangements offer a major and unrivalled opportunity to improve the quality and safety of patient care and to reduce health inequalities. Our most important message was that doctors must be enabled to work together across traditional organisational boundaries to meet the aspirations and needs of patients".

I therefore welcome this debate in the Postgraduate Medical Journal about medicine in the community. Getting the relationship right between consultants and general practitioners is one of the most pressing questions in the NHS today. What do general practitioners want to do and what do consultants want to do?

It is estimated that 17 million adults in the UK live with one or more chronic longterm conditions and the inverse care law continues to operate widely in the NHS. The big challenge for medicine in the community in the 21 st century will be long-term conditions and comorbiditythe presence of one or more apparently unrelated conditions. Comorbidity is more commonly distributed among the deprived communities and this brings another big challenge to the fore-that of narrowing health inequalities. Both these are essential tasks for generalists who co-ordinate care. Empowering patients and health promotion will also be key objectives.

To tackle these problems we need new models of care, and to be creative in our thinking. It is my belief that services must be co-ordinated and delivered through integrated healthcare teams in the community 
that are focused around the primary care practice with effective professional leadership and information. We are used to the concept of multidisciplinary team working both in primary and secondary care. Now we need partnerships across the previously sacrosanct boundaries of primary and secondary care. The language of primary and secondary care is becoming increasingly redundant. We should therefore use the terms "generalist" and "specialist".

Patients are best served by an appropriate balance of generalist and specialist skills: the benefit to patients of adequate numbers of specialists is undermined if there are insufficient general practitioners, or vice versa. The partnership between generalists and specialists needs to be focused within the community and not within the hospital and must encompass service, education, research and audit. In the model proposed by the RCGP and the RCP, clinicians would champion and lead local health economies. Groups of doctors and related healthcare professionals should be responsible for the healthcare of a geographically defined population. Commissioning must not become a tussle between specialists and generalists; instead, the focus should be on the development of care pathways. Most care, including that for mental health, can be given in the community; hospitals should be for acutely ill patients or where a specialised procedure or treatment is required. ${ }^{3}$

Primary healthcare is delivered by teams, increasingly getting larger. Integration is crucial and it is possible to envisage specialists working as part of the team in a non-hierarchical way. The formation of effective teams first requires a shared characteristic or goal that is distinctive and specific to the members, and requires all members to work together to accomplish clear outcomes using individual end products. Although team members may not always be co-located, they will be united through their common focus on the delivery of high-quality healthcare to all patients facilitated by strong working relationships.

The future also brings with it the opportunity for joint education and training both at specialist level and after Certificate of Completion of Training. This will inevitably require new training models, shared where appropriate, with trainees moving seamlessly between what are currently defined as primary and secondary care. But as professional boundaries become increasingly blurred, it is essential that doctors work within their defined and verified areas of competence to ensure the quality and safety of patient care.

The central gate-keeping or navigation role of the general practitioner must be retained to ensure the most appropriate pathway for patients and use of resources.
To maintain the effectiveness and efficiency of the health service ${ }^{4}$ it is essential to ensure that access to specialists is through generalists by the use of the registered list and the gate-keeping or navigation function. There is a temptation to allow direct access for patients to specialists or any doctor, which is the feature of a "free market"; but this would be counter to the weight of thinking in health policy and risks fragmenting care, reducing quality and increasing costs.

Generalists and specialists working together in the community in new models is an exciting and enticing prospect. However, care must be taken to ensure that it is undertaken in a managed way and evaluated.

Postgrad Med J 2007;83:71-72.

doi: 10.1136/pgmi.2006.056226

Correspondence to: Royal College of General Practitioner, 14 Princes Gate, Hyde Park, London SW7 IPU, UK; mlakhani@rcgp.org.uk

\section{REFERENCES}

1 Department of Health. Our health, our care, our say: a new direction for community services. London: $\mathrm{DH}, 2006$.

2 RCGP/RCP Statement. Making the best use of doctors' skills-a balanced partnership. www.rcgp.org.uk.

3 Lakhani M, Baker M. Visions of primary care in 2015: good general practitioners will continue to be essential. BMJ 2006:332:41-3.

4 Starfield B. The effectiveness of primary healthcare. In: Lakhani MK, ed. A celebration of general practice. Abingdon: Raddliffe Medical Press, 2003:19-36.

\section{Specialist services in the community: maintaining quality of care}

\section{Mary Armitage}

\section{The need for joint training programmes and collaborative partnerships}

$\mathrm{T}$ he length of specialist medical training and past imprecision in medical workforce planning has led to relative inflexibility when developing new models of service delivery. Specialist care in the community may provide more convenient and accessible care for patients, but must not be at the expense of quality. It is important that new models of care are evaluated through pilots, for quality of care and cost effectiveness, before widespread implementation.

This care will require close collaborative working between all members of the multidisciplinary team and the Royal College of Physicians and the Royal

College of General Practitioners have signalled their wish to encourage working together across traditional professional boundaries to facilitate new models of service delivery. This will require new training models, with trainees moving seamlessly between what are currently defined as primary and secondary care. There are opportunities for joint education and training at a specialist level, and after Certificate of Completion of Training.

Many aspects of community care are embedded in hospital-based specialist training, including regular medication review, health education, the promotion of a healthy lifestyle and disease prevention as well as team working. However, other aspects of community healthcare, including providing treatments in the home, working alongside a community-based multidisciplinary team, relationships with community social care and additional business management skills represent new challenges for the hospital trainees, who will need to spend time working in the community setting. Equally, general practitioners with a specialist interest need to be integrated within the local service model, with close working and training relationships with the secondary care specialist service.

The key issue is that all healthcare workers delivering specialist services work to agreed national standards of practice. Competency-based training and assessments should facilitate new training programmes to deliver the agreed specialist competencies. Joint training programmes will enable specialist care to be delivered in the community, and will build on collaborative partnerships to improve the service for patients.

Postgrad Med J 2007;83:72. doi: $10.1136 /$ pgmi.2006.056093

Correspondence to: Clinical Vice President, Royal College of Physicians, 11 St Andrews Place, Regent Park, London NW1 4LE, UK 